\title{
Distinct Short-Range Order Is Inherent to Small Amorphous Calcium Carbonate Clusters ( $<\mathbf{2} \mathbf{~ n m})$
}

\author{
Shengtong Sun, Daniel M. Chevrier, Peng Zhang, Denis Gebauer,* and Helmut Cölfen*
}

\begin{abstract}
Amorphous intermediate phases are vital precursors in the crystallization of many biogenic minerals. While inherent short range orders have been found in amorphous calcium carbonates (ACCs) relating to different crystalline forms, it has never been clarified experimentally whether such orders already exist in very small clusters less than $2 \mathrm{~nm}$ in size. Here, we studied the stability and structure of 10,12 pentaco sadiynoic acid (PCDA) protected ACC clusters with a core size of ca. $1.4 \mathrm{~nm}$ consisting of only seven $\mathrm{CaCO}_{3}$ units. Ligand concentration and structure are shown to be key factors in stabilizing the ACC clusters. More importantly, even in such small $\mathrm{CaCO}_{3}$ entities, a proto calcite short range order can be identified but with a relatively high degree of disorder that arises from the very small size of the $\mathrm{CaCO}_{3}$ core. Our findings support the notion of a structural link between prenucleation clusters, amorphous intermediates, and final crystalline poly morphs, which appears central to the understanding of polymorph selection.
\end{abstract}

A A early stages of mineral formation, are important precursors in the crystallization of many biogenic minerals such as sea urchin spicules ${ }^{[1]}$ and plant cystoliths. ${ }^{[2]}$ In recent years, plenty of evidence has been found for a "nonclassical" nucleation route of minerals involving prenucleation clusters as inter mediate precursors. ${ }^{[35]}$ Stable prenucleation clusters were first discovered in $\mathrm{CaCO}_{3}$ precipitation, ${ }^{[3]}$ and were also reported for other systems like calcium phosphate, ${ }^{[6]}$ magnet ite, ${ }^{[7]}$ and silica. ${ }^{[8]}$ In the case of $\mathrm{CaCO}_{3}$, according to the hypothetical prenucleation cluster pathway, crystallization proceeds through the formation of amorphous calcium carbonate (ACC) by the aggregation of nanodroplets that

[*] Dr. S. T. Sun, Dr. D. Gebauer, Prof. Dr. H. Cölfen Physical Chemistry, University of Konstanz

Universitätsstrasse 10, 78457 Konstanz (Germany)

E mail: denis.gebauer@uni konstanz.de

helmut.coelfen@uni konstanz.de

D. M. Chevrier, Prof. Dr. P. Zhang

Department of Chemistry and Institute for Research in Materials Dalhousie University

Halifax, Nova Scotia B3H 4R2 (Canada)

Dr. S. T. Sun

Current address: School of Chemical Engineering

State Key Laboratory of Chemical Engineering, Shanghai Key

Laboratory of Multiphase Materials Chemical Engineering

East China University of Science and Technology

130 Meilong Road, Shanghai 200237 (P.R. China) directly emerge from prenucleation clusters upon phase separation, and subsequent transformation into crystals.

The $\mathrm{CaCO}_{3}$ prenucleation clusters with a size between $0.61 .1 \mathrm{~nm}^{[9]}$ and $2 \mathrm{~nm}^{[3]}$ were shown by computer simulation to be disordered, flexible, and strongly hydrated liquid like ionic polymers with a dynamic topology of chains, branches, and rings. ${ }^{[10]}$ Titration results of $\mathrm{CaCO}_{3}$ precipitation implied a link between binding strength in prenucleation clusters and the type of postnucleation amorphous phase, suggesting that short range order discovered in $\mathrm{ACCs}^{[11}{ }^{18]}$ may already exist in the prenucleation clusters. ${ }^{[3]}$ However, experimental inves tigation or verification of the structure of $\mathrm{CaCO}_{3}$ clusters is quite challenging. First, it requires stopping the process of precipitation at the initial stages and isolating prenucleation clusters. Second, if the cluster can be stabilized, the hybrid structure must be well defined for easy analysis. A few efforts have been made to stabilize and elucidate the $\mathrm{CaCO}_{3}$ cluster structure. For example, the addition of silica was shown to be able to effectively suppress the nucleation of $\mathrm{CaCO}_{3}$ clusters even at high supersaturation. ${ }^{[19]}$ However, the probable existence of silica particles and silica associated clusters as well as other salts made the isolation and structural character ization of $\mathrm{CaCO}_{3}$ clusters difficult. Poly(acrylic acid) appeared to also stabilize ACC nanograins sized $23 \mathrm{~nm}$, but the formed nanocomposite structure renders isolation and detailed analysis of $\mathrm{CaCO}_{3}$ clusters improbable. ${ }^{[20]}$

In our previous study, we found a unique amphipathic ligand, 10,12 pentacosadiynoic acid (PCDA), that can effec tively stabilize ACC with a very small core size of ca. $1.4 \mathrm{~nm}$, which was used for subsequent investigation of its crystal lization behavior. ${ }^{[21]}$ Preliminary characterizations showed that the particle (named ACC cluster) might have a micellar structure involving an ACC core decorated by PCDA chains with the structural composition of $\left(\mathrm{CaCO}_{3}\right)_{7}\left(\mathrm{H}_{2} \mathrm{O}\right)_{4}(\mathrm{PCDA})_{3}$. It is noted that the size of the $\mathrm{CaCO}_{3}$ core in the $\mathrm{ACC}$ cluster is quite comparable to that of prenucleation clusters in aqueous solution, and the number of $\mathrm{CaCO}_{3}$ units in the cluster is close to that in the primitive rhombohedral unit cell of calcite (consisting of six ion pairs). ${ }^{[15,22]}$ Therefore, it would be interesting to know whether a distinct short range order still exists in such a small $\mathrm{CaCO}_{3}$ entity.

Given the highly dynamic character of $\mathrm{CaCO}_{3}$ prenuclea tion clusters in aqueous solution, ${ }^{[10]}$ we examined the stability of the PCDA protected ACC cluster towards crystallization. Unexpectedly, at room temperature, the ACC clusters can be stored in toluene or in dry state for at least six months without any change. Furthermore, the ACC clusters are very stable under the action of heat $\left(100^{\circ} \mathrm{C}\right.$ for 4 days, Figure S1), water vapor, and several additives, or under electron beam irradi ation in the transmission electron microscope (TEM). 
To verify the specific role of PCDA in stabilizing the ACC cluster, we studied the effect of PCDA concentration on producing ACC clusters. As shown in Figure 1, only when the
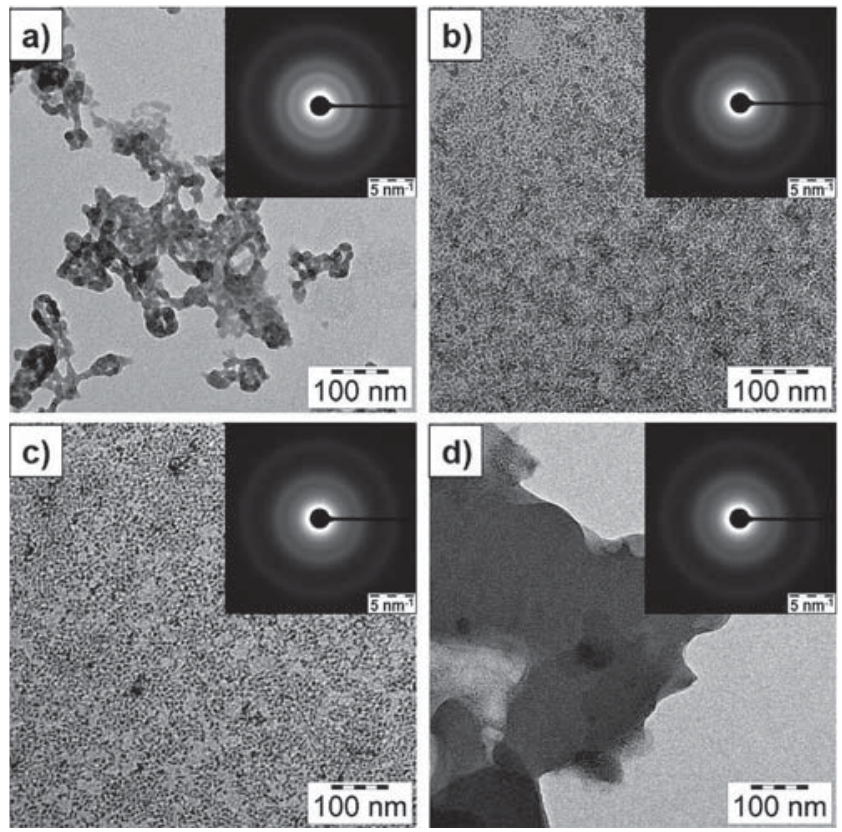

Figure 1. TEM images and corresponding SAED patterns of $\mathrm{CaCO}_{3}$ synthesized at different concentrations of PCDA: a) $2 \mathrm{~mm}$; b) $3 \mathrm{~mm}$; c) $4 \mathrm{~mm}$; d) $10 \mathrm{~mm}$.

concentration of PCDA is $4 \mathrm{~mm}$ can perfect clusters be formed. A lower concentration of PCDA ( $2 \mathrm{~mm})$ is not able to stabilize small clusters, resulting in large amorphous particles (10 $15 \mathrm{~nm}$ ), while higher levels of PCDA (10 mM) often result in a hybrid layered structure of PCDA and clusters. A transient phase can be observed when the concentration of PCDA is $3 \mathrm{~mm}$. Apparently, the PCDA concentration is a key factor for the formation of stable ACC clusters. This is consistent with the fact that the optimized concentration of PCDA (4 mm) corresponds to the feed ratio of $\left[\mathrm{Ca}^{2+}\right] /[\mathrm{PCDA}]$ of 2.32 .5 which is in good accordance with the proposed molecular formula of the ACC cluster, $\left(\mathrm{CaCO}_{3}\right)_{7}\left(\mathrm{H}_{2} \mathrm{O}\right)_{4}(\mathrm{PCDA})_{3}$, for nearly $100 \%$ conversion in terms of $\mathrm{Ca}^{2+}$. While it is still not clear why PCDA can stabilize such small ACC clusters, the number of $\mathrm{CaCO}_{3}$ units seven finds support in recent ab initio simulations where the stabilization energy per monomer appears to reach a plateau at this size. ${ }^{[23]}$

Moreover, control experiments with additional ligands (Figures S2,3) show that besides PCDA, oleic acid and sodium bis( 2 ethylhexyl)sulfosuccinate (NaAOT) can stabilize a small amount of clusters. It is speculated that only fatty acids with long alkyl chains and low chain order effectively stabilize the $\mathrm{CaCO}_{3}$ clusters, especially when we compare the chemical structures of oleic acid and stearic acid which have the same chain length but different degrees of structural saturation. Long alkyl chains are known to be favorable for the formation of stable self assembled monolayers with high ligand coverage and can provide substantial barriers to water and ion penetration. ${ }^{[24]}$ The diacetylene group or double bond existing in the long alkyl chain may interrupt the chain order during the binding process on $\mathrm{CaCO}_{3}$, which consequently hinders the formation of ordered $\mathrm{CaCO}_{3}$ crystallites.

As the diacetylene group of PCDA is easily polymerized by light irradiation, ${ }^{[25]}$ it is essential to know whether the PCDA monolayer polymerizes during reaction and posttreat ment. The similarity between the UV/Vis absorption of ACC clusters and PCDA in hexane (Figure $2 \mathrm{a}$ ) shows that the

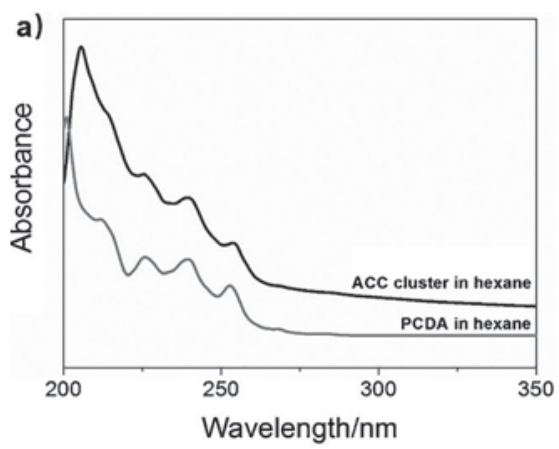

b)

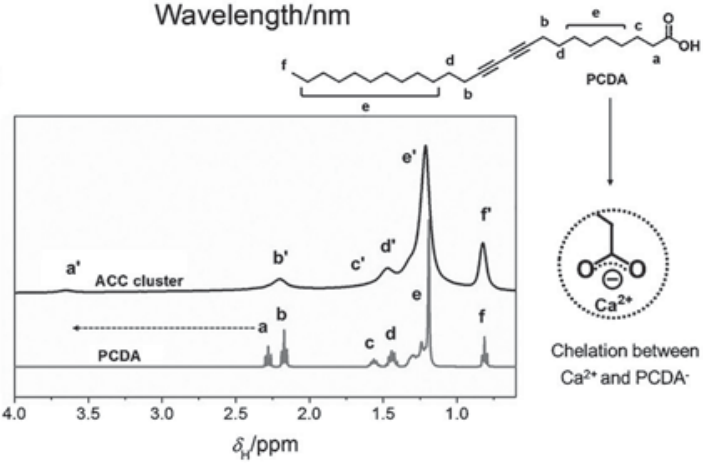

Figure 2. a) UV/Vis spectra of ACC clusters and PCDA in hexane. b) ${ }^{7} \mathrm{H}$ NMR spectra and corresponding resonance assignments of ACC clusters and PCDA in [D]chloroform. $a, b, c, \ldots$ represent hydrogens in PCDA while $a^{\prime \prime}, b^{\prime \prime}, c^{\prime \prime}, \ldots$ represent hydrogens in the ACC cluster.

PCDA chains in the ACC clusters are still in their monomeric form after binding on the $\mathrm{CaCO}_{3}$ core. No absorption in the visible region can be observed, corresponding to the good transparency of dispersions of ACC clusters due to their small size. Raman spectroscopy further confirmed the monomeric form of PCDA chains (Figure S4). Compared to PCDA, the ${ }^{1} \mathrm{H}$ NMR spectrum of ACC clusters in [D]chloroform exhibits a resonance peak broadening effect, and a large shift of $\mathrm{H}_{\mathrm{a}}$ (to $\mathrm{H}_{\mathrm{a}^{\prime}}$ ) corresponding to the methylene group adjacent to $\mathrm{COOH}$, indicating the chelation between $\mathrm{Ca}^{2+}$ and PCDA.

That the PCDA chains are bound to $\mathrm{Ca}$ ions within clusters is also evidenced by the shift of the $\mathrm{C}=\mathrm{O}$ stretching band from COOH $\left(1690 \mathrm{~cm}^{-1}\right)$ to $\mathrm{COO}^{-}\left(1547 \mathrm{~cm}^{-1}\right)$ in the IR spectra (Figure 3). The broad band between 3600 and $3200 \mathrm{~cm}^{-1}$ is due to the structural water in the cluster, suggesting that the $\mathrm{CaCO}_{3}$ core is hydrated. Interestingly, by comparison with synthetic ACC with known composition, the ACC cluster core corresponds to $\mathrm{CaCO}_{3} \cdot 0.57 \mathrm{H}_{2} \mathrm{O}$ (Fig ure $\mathrm{S} 5$ ), which is also in accord with the proposed molecular formula of the ACC cluster, $\left(\mathrm{CaCO}_{3}\right)_{7}\left(\mathrm{H}_{2} \mathrm{O}\right)_{4}(\mathrm{PCDA})_{3} \cdot{ }^{[21]}$ The alkyl chains of PCDA are partly converted to gauche 


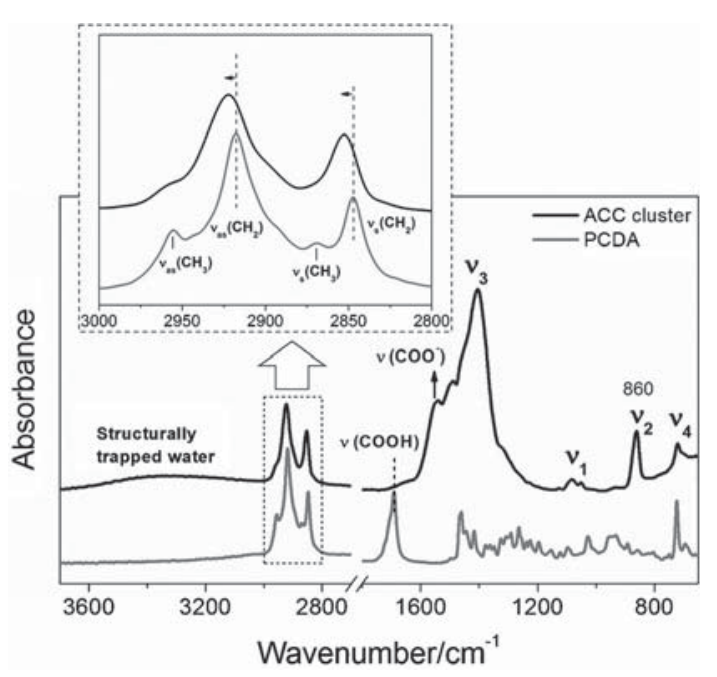

Figure 3. ATR FTIR spectra of ACC clusters and PCDA. The inset shows an enlarged view of the $\mathrm{C} \mathrm{H}$ stretching region shown in the dashed box.

conformations upon binding to the $\mathrm{CaCO}_{3}$ core, as evident from the shift of the $\mathrm{C} \mathrm{H}$ stretching bands of the ACC cluster to larger wavenumbers (inset in Figure 3). ${ }^{[26]}$ More impor tantly, the $v_{1} v_{4}$ bands can be used to relate the structure of the ACC cluster to distinct amorphous forms. ${ }^{[16,17]}$ The $v_{1}$ and $v_{4}$ bands are partially superimposed by vibrational modes of PCDA, but the $v_{2}$ and $v_{3}$ modes of ACC cluster at $860 \mathrm{~cm}^{-1}$ and $1399 / 1462 \mathrm{~cm}^{-1}$ (double band) are very close to that of proto calcite ACC at $862 \mathrm{~cm}^{-1}$ and 1392/1462 $\mathrm{cm}^{-1}$, ${ }^{[16]}$ respec tively. This indicates the small ACC clusters exhibit a proto calcite short range order in the $\mathrm{CaCO}_{3}$ core

To further prove the existence of proto calcite order in the ACC clusters, we performed solid state ${ }^{13} \mathrm{C}$ NMR analysis. Note that the sample for NMR was ${ }^{13} \mathrm{C}$ enriched, so as to avoid any interference from PCDA chains. The clusters were prepared by changing the $\mathrm{CO}_{2}$ supply from $\left(\mathrm{NH}_{4}\right)_{2} \mathrm{CO}_{3}$ decomposition to the rapid release of ${ }^{13} \mathrm{CO}_{2}$ via addition of $\mathrm{HCl}$ to $\mathrm{Na}_{2}{ }^{13} \mathrm{CO}_{3}$. TEM, IR, and ${ }^{1} \mathrm{H}$ NMR studies all indicate the similarity of the ACC clusters, independent of the supply source of $\mathrm{CO}_{2}$ (Figures S6,7). As shown in Figure 4a, a broad resonance centered at $168.5 \mathrm{ppm}$ can be observed in the solid state ${ }^{13} \mathrm{C}$ NMR spectrum of the ACC clusters, which agrees with that of both calcite and proto calcite ACC (168.7 ppm) within experimental accuracy. ${ }^{[16]}$ The full width at half maximum (FWHM) of ca. $3.8 \mathrm{ppm}$ for the ACC clusters is even larger than that of proto calcite $\operatorname{ACC}(3.6 \mathrm{ppm}) .^{[16]}$ This indicates that the $\mathrm{CaCO}_{3}$ core of the ACC clusters indeed exhibits a proto calcite structure but with a relatively high degree of disorder that likely arises from the very small size of the ACC cluster core. Despite the discovery of several proto crystalline forms of short range order in ACC (or polya morphism) $\left.,{ }^{[16} 18,27,28\right]$ the here reported finding of the existence of short range order in very small ACC clusters less than $2 \mathrm{~nm}$ has never been reported, which also supports the relevance of the preformed short range order in prenucleation clusters. ${ }^{[3]}$

We further employed $\mathrm{Ca} \mathrm{K}$ edge $\mathrm{X}$ ray absorption analyses to investigate the internal structure of the ACC a)
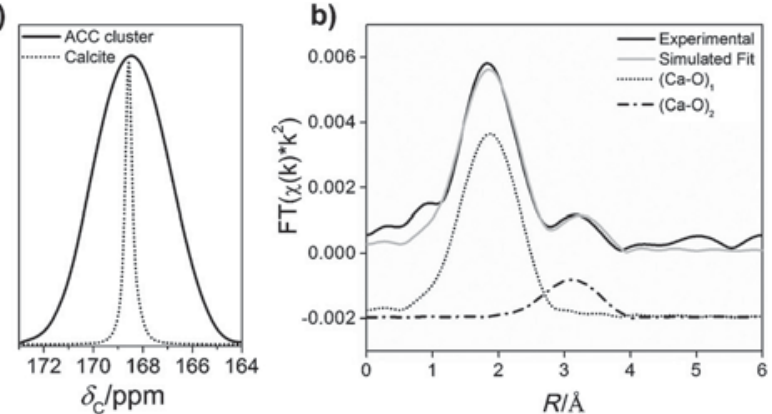

Figure 4. a) Solid state ${ }^{13} \mathrm{C}$ NMR spectra of ACC clusters and calcite. The resonance at $168.5 \mathrm{ppm}$ suggests that the $\mathrm{CaCO}_{3}$ core in the ACC clusters exhibits a proto calcite structure. The FWHM is ca. $3.8 \mathrm{ppm}$. b) Fourier transform of $\mathrm{Ca} \mathrm{K}$ edge EXAFS plotted in the $R$ space. The fitted curves of the first two $\mathrm{Ca} O \mathrm{O}$ coordination shells are shown at the bottom with an offset of 0.002 units.

clusters. In the $\mathrm{Ca} \mathrm{K}$ edge extended $\mathrm{X}$ ray absorption fine structure (EXAFS) spectrum of the ACC clusters (Fig ure 4 b), a large Debye Waller factor $\left(\sigma^{2}\right)$ of $0.015 \pm 0.004 \AA^{2}$ for the first shell and a small coordination number of 2 for the second shell (EXAFS fitting results in Table S1) further demonstrate a small $\mathrm{CaCO}_{3}$ cluster size and a rather disor dered nature of $\mathrm{Ca}$ sites with a mix of $\mathrm{Ca} \mathrm{O}$ coordination geometries and bond lengths. ${ }^{[16,29,30]}$ Comparison of $\mathrm{Ca} \mathrm{K}$ edge $\mathrm{X}$ ray absorption near edge structure (XANES) spectra of ACC cluster, proto calcite ACC and calcite further support that ACC clusters are relatively disordered (Figure S8). Furthermore, a simulated Ca K edge XANES spectrum for the optimized cluster model ${ }^{[21]}$ shows the emergence of a prominent near edge feature at $23 \mathrm{eV}$ compared with calcite again indicating the small size of the ACC clusters with a high degree of disorder.

It should be noted that, despite the confirmed existence of short range order in such small ACC clusters, it remains unclear how the short range order arises from. The ACC cluster might have a hydrated chain like structure as shown in the simulation of prenucleation clusters. ${ }^{[10]}$ Recently, Rez et al. proposed a nanocrystallite model for ACC where randomly oriented nanocrystals with a size of ca. $1 \mathrm{~nm}$ could give rise to coherent diffraction profiles that are characterized as amorphous, and water molecules fill in the spaces between the distorted nanocrystallites. ${ }^{[22]}$ However, in the case of the present ACC clusters, the lack of $\mathrm{CaCO}_{3}$ units for constructing a single nanocrystalline calcite unit cell and the fact that water molecules can be present only in the cluster core, due to the hydrophobicity of the ligand, exclude this possibility. Owing to the rather small size of the $\mathrm{CaCO}_{3}$ core, a radial water distribution, with the outer shell being more hydrated than the inner core as observed for larger ACC particles, ${ }^{[31]}$ is not expected for these ACC clusters.

Altogether, in this study, we elucidated the principles for producing stable ACC clusters through ligands (proper concentration, long alkyl chain and low chain order) and in detail characterized the ACC cluster protected by PCDA chains. What is more important, for the first time we discovered the inherent ACC like short range order of proto calcite existing in ACC clusters with a size less than 
$2 \mathrm{~nm}$ and only seven $\mathrm{CaCO}_{3}$ units, but with a high degree of disorder due to the very small size, which is reminiscent of the structure of prenucleation clusters in the solution case. Our findings demonstrate that species which contain as few $\mathrm{CaCO}_{3}$ units as are approximately contained in the primitive unit cell of calcite can already have a proto calcite short range order. This has far reaching implications for our understand ing of crystallization and polymorph control, since structural information can be encoded already in smallest clusters with sizes as small as prenucleation clusters.[SS1]

\section{Acknowledgements}

S.T.S gratefully acknowledges financial support from the Alexander von Humboldt Foundation. D.G. is a Research Fellow of the Zukunftskolleg of the University of Konstanz, and supported by the Fonds der Chemischen Industrie. This work was also supported by the facilities in the Nanostructure Laboratory, NMR Core Center and Proteomics Center of the University of Konstanz. D.M.C. acknowledges funding sup port from the Alexander Graham Bell NSERC scholarship. P.Z. acknowledges funding support from Dalhousie Univer sity and NSERC in the form of discovery grants. The Canadian Light Source (CLS) is financially supported by NSERC Canada, CIHR, NRC and the University of Sas katchewan. CLS@APS (Sector 20 BM) facilities at the Advanced Photon Source (APS) (Argonne National Labo ratory) and research at these facilities are supported by the U.S. Department of Energy Basic Energy Sciences, a Major Resources Support grant from NSERC, the University of Washington, the CLS, and the APS. Use of the APS and Office of Science User Facility operated for the U.S. Depart ment of Energy Office of Science by Argonne National Laboratory, was supported by the U.S. DOE under Contract No. DE AC02 06CH11357. We thank Dr. Marina Krumova for TEM imaging, Matthias Altenburg for Raman measure ments, Masoud Farhadi Khouzani for valuable discussions, and Dr. Robert Gordon and Dr. Zou Finfrock at CLS@APS (Sector 20 BM) facilities for technical assistance.

Keywords: amorphous materials - calcium carbonate clusters . carboxylate ligands · EXAFS · short range order

[1] Y. Politi, T. Arad, E. Klein, S. Weiner, L. Addadi, Science 2004, 306, 11611164

[2] A. Gal, W. Habraken, D. Gur, P. Fratzl, S. Weiner, L. Addadi, Angew. Chem. Int. Ed. 2013, 52, 4867 4870; Angew. Chem. 2013, 125, 49674970.

[3] D. Gebauer, A. Völkel, H. Cölfen, Science 2008, 322, 18191822.

[4] D. Gebauer, H. Cölfen, Nano Today 2011, 6, 564584.

[5] D. Gebauer, M. Kellermeier, J. D. Gale, L. Bergström, H. Cölfen, Chem. Soc. Rev. 2014, 43, 23482371.
[6] A. Dey, P. H. H. Bomans, F. A. Müller, J. Will, P. M. Frederik, G. de With, N. Sommerdijk, Nat. Mater. 2010, 9, 10101014.

[7] J. Baumgartner, A. Dey, P. H. H. Bomans, C. Le Coadou, P. Fratzl, N. A. J. M. Sommerdijk, D. Faivre, Nat. Mater. 2013, 12, 310314.

[8] A. I. Lupulescu, J. D. Rimer, Science 2014, 344, 729732.

[9] E. M. Pouget, P. H. H. Bomans, J. Goos, P. M. Frederik, G. de With, N. Sommerdijk, Science 2009, 323, 14551458.

[10] R. Demichelis, P. Raiteri, J. D. Gale, D. Quigley, D. Gebauer, Nat. Commun. 2011, 2, 590.

[11] M. G. Taylor, K. Simkiss, G. N. Greaves, M. Okazaki, S. Mann, Proc. R. Soc. London Ser. B 1993, 252, 7580.

[12] A. Becker, U. Bismayer, M. Epple, H. Fabritius, B. Hasse, J. Shi, A. Ziegler, Dalton Trans. 2003, 551555.

[13] C. Günther, A. Becker, G. Wolf, M. Epple, Z. Anorg. Allg. Chem. 2005, 631, 28302835.

[14] Y. Politi, Y. Levi Kalisman, S. Raz, F. Wilt, L. Addadi, S. Weiner, I. Sagi, Adv. Funct. Mater. 2006, 16, 12891298.

[15] R. Gueta, A. Natan, L. Addadi, S. Weiner, K. Refson, L. Kronik, Angew. Chem. Int. Ed. 2007, 46, 291 294; Angew. Chem. 2007, 119, 295298.

[16] D. Gebauer, P. N. Gunawidjaja, J. Ko, Z. Bacsik, B. Aziz, L. Liu, Y. Hu, L. Bergström, C. W. Tai, T. K. Sham, M. Edén, N. Hedin, Angew. Chem. Int. Ed. 2010, 49, 8889 8891; Angew. Chem. 2010, 122, 90739075.

[17] J. H. E. Cartwright, A. G. Checa, J. D. Gale, D. Gebauer, C. I. Sainz Diaz, Angew. Chem. Int. Ed. 2012, 51, 11960 11970; Angew. Chem. 2012, 124, 1212612137.

[18] M. Farhadi Khouzani, D. M. Chevrier, P. Zhang, N. Hedin, D. Gebauer, Angew. Chem. Int. Ed. 2016, 55, 8117 8120; Angew. Chem. 2016, 128, 82498252.

[19] M. Kellermeier, D. Gebauer, E. Melero Garcia, M. Drechsler, Y. Talmon, L. Kienle, H. Cölfen, J. M. Garcia Ruiz, W. Kunz, $A d v$. Funct. Mater. 2012, 22, 43014311.

[20] Y. Oaki, S. Kajiyama, T. Nishimura, H. Imai, T. Kato, Adv. Mater. 2008, 20, 36333637.

[21] S. Sun, D. Gebauer, H. Cölfen, unpublished results.

[22] P. Rez, S. Sinha, A. Gal, J. Appl. Crystallogr. 2014, 47, 1651 1657.

[23] V. M. Rosas García, I. D. Sáenz Tavera, D. E. Cantú Morales, J. Cluster Sci. 2012, 23, 203219.

[24] M. D. Porter, T. B. Bright, D. L. Allara, C. E. D. Chidsey, J. Am. Chem. Soc. 1987, 109, 35593568.

[25] O. Yarimaga, J. Jaworski, B. Yoon, J. M. Kim, Chem. Commun. 2012, 48, 24692485.

[26] A. Saito, Y. Urai, K. Itoh, Langmuir 1996, 12, 39383944.

[27] A. Fernandez Martinez, B. Kalkan, S. M. Clark, G. A. Way chunas, Angew. Chem. Int. Ed. 2013, 52, 8354 8357; Angew. Chem. 2013, 125, 85128515.

[28] W. Peng, X. Chen, S. Zhu, C. Guo, C. L. Raston, Chem. Commun. 2014, 50, 1176411767.

[29] Y. Levi Kalisman, S. Raz, S. Weiner, L. Addadi, I. Sagi, $A d v$. Funct. Mater. 2002, 12, 4348.

[30] F. M. Michel, J. MacDonald, J. Feng, B. L. Phillips, L. Ehm, C. Tarabrella, J. B. Parise, R. J. Reeder, Chem. Mater. 2008, 20, 47204728.

[31] P. Raiteri, J. D. Gale, J. Am. Chem. Soc. 2010, 132, 1762317634. 